\title{
Nutrição e Desenvolvimento
}

\author{
Nutrition and Development
}

\author{
IIma K. G. de Arruda ${ }^{1}$ \\ Bertoldo K. G. de Arruda ${ }^{1}$
}

\begin{abstract}
ARRUDA, I. K. G. E ARRUDA, B. K. G. Nutrition and Development. Cad. Saúde Públ., Rio de Faneiro, 10 (3): 392-397, Ful/Sep, 1994.
\end{abstract}

Discussions on development and nutrition frequently have a double focus: one that considers nutritional status as a reflection of development, and another that admits that nutrition strongly influences the level and rhythm of development. The authors view nutrition as a decisive factor for adequate social and economic development, specifying the fact that nutritional interventions might contribute to significant improvements in individual classroom performance, productivity at the workplace, and resistance to infections. The implications of malnutrition for the economy are thus evident: either by limitations in income expectations, increased costs deriving from burdens assumed by the population to protect themselves, or considerable hidden social costs — absenteeism, work accidents, and rotation of employees. Given modernization and a competitive economy, there is an unquestionable need for nutrition to head the agenda of national priorities, thus promoting human resource development and the preservation of this human capital, one of the chief goals of a socially responsible economy.

Key words: Nutrition; Development; Public Policies; Human Resources

\section{INTRODUÇÃO}

Testemunhamos, nos dias atuais, uma vigorosa arregimentação de esforços para enfrentamento do desafio de resgatar a enorme dívida social, configurada por cerca de um terço da população brasileira na pobreza absoluta e metade desse terço na indigência.

O eixo nuclear dessas ações está consubstanciado no Plano de Combate à Fome e à Miséria, onde um dos pólos de atuação se direciona à luta contra a pobreza estrutural, que é uma condição dependente do desenvolvimento, isto é, da ampliação das capacidades de toda a sociedade e dos indivíduos que a compõem.

Alerta a Organização Panamericana de Saúde (1990), que superar os estrangulamentos do desenvolvimento é a única fórmula de empreender a rota do progresso efetivo, acentuando a necessidade crescente de muitos países das Américas darem atenção prioritária ao capi-

${ }^{1}$ Instituto Materno Infantil de Pernambuco. Rua dos Coelhos, 300, Recife, PE, 50070-550, Brasil. tal humano que conforma seus povos, inquestionavelmente $o$ instrumento indispensável para a expressão plena de suas potencialidades criativas e produtivas.

Assim, cada ser humano representa um capital que, diz Musgrove (1993), mais do que a simples conotação de produtividade econômica é, essencialmente, a soma de suas habilidades e conhecimentos, aduzindo que o capital biológico é mais suscetível aos riscos que outros tipos de capital.

Dentre os riscos que podem comprometer seriamente a elevação e qualificação das supracitadas características, assumem particular relevo as deficiências nutricionais. Deste modo, se o fundamental para o desenvolvimento é o homem e se se aceita a qualidade de vida como objetivo do desenvolvimento, a Nutrição adquire importância inconteste como meio para alcançá-lo.

As discussões nesse campo estão ganhando novas e significativas dimensões e talvez estejamos mais bem preparados para responder essas críticas de Hakim \& Solimano (1976), que cobram dos defensores da Nutrição provas mais 
convincentes de que a desnutrição é o maior obstáculo a esforços mais amplos em direção ao desenvolvimento econômico, e também a confiabilidade de estudos que extrapolam para dimensão nacional o efeito de deficiências nutricionais sobre o indivíduo.

Em que pesem as argumentações de que o estado nutricional é reflexo do desenvolvimento, está crescendo a legião dos que advogam a influência da nutrição no nível e ritmo desse desenvolvimento, reconhecendo o capital humano como um dos capitais fundamentais para promovê-lo. Daí a pertinência da observação de Berg (1974), ao analisar a repercussão das carências nutricionais sobre o potencial econômico do homem, de que devemos deslocar o enfoque da Nutrição, considerando-a mais um fator de desenvolvimento do que de bem-estar.

\section{PRINCIPAIS DELINEAMENTOS}

Pretendemos, nos limites deste artigo, realizar uma abordagem exploratória dos agravos nutricionais referidos na literatura como de maior repercussão na economia. Portanto, este texto cumpre o papel de position paper, a fim de despertar o interesse para análises de maior profundidade.

Nessa temática, salienta Berg (1985), ainda são desconhecidos muitos dos efeitos da desnutrição sobre o desenvolvimento, refletindo, em parte, a novidade sobre o tema e, em parte, a complexidade para determinar o desempenho e o desenvolvimento do homem.

No Brasil, os inquéritos mais recentes revelam a freqüência aumentada de certas características antropométricas - a estatura reduzida e o baixo peso corporal - indicativas da ocorrência da desnutrição em estágios diferenciados nos períodos iniciais do ciclo vital.

Outrossim, o nanismo é referido constantemente no noticiário da imprensa, como indicador de padrões nutricionais inaceitáveis de numerosos contingentes da nossa população. Sabe-se, em relação às crianças nanicas, que suas realizações e comportamento acompanham mais a estatura do que a idade.

Estudos da Organização Mundial de Saúde (OMS), referidos por Berg (1975), concluíram que uma criança de seis anos com o desenvolvimento físico de uma de três, não pode ser comparada em capacidade de aprendizagem e comportamento a qualquer dos dois grupos etários - é um ser substancialmente diferente, com características biológicas e de comportamento próprios.

Certamente, um dos acometimentos mais comprometedores da desnutrição é no tocante a capacidade mental, que se manifesta desde o período fetal.

Nas revisões da literatura, conforme Berg (1981: 11), está demonstrado "que a diminuição do crescimento, tanto em estatura como em peso, associada com diversos graus de má nutrição é acompanhada de diminuição da circunferência do crânio, do tamanho do cérebro, do número de células cerebrais e também, em casos menos graves, de déficits nos resultados das provas de capacidade cognitiva e sensorial". As avaliações realizadas revelaram que "todas as regiões cerebrais são afetadas, embora diferentemente, pela diminuição da divisão celular que acompanha a nutrição em idade precoce, no ventre materno e no primeiro ano de vida". Por sua vez, a constatação mais preocupante na cronologia da deficiência foi a de que "as crianças que se rehabilitaram depois de uma má nutrição grave seguem atrasadas no desenvolvimento da atividade motora, da audição, da linguagem, do comportamento social e pessoal, da capacidade de resolver problemas, da coordenação manual e visual e do pensamento abstrato".

Nesse contexto, a irreversibilidade do dano é um aspecto que vem polarizando as discussões.

Entretanto, consta de documento da Conferência Internacional sobre Nutrição (FAO/ OMS, 1992a: 08), que “um estudo inovador de Martorell et al., realizado na Guatemala, localizou ao fim de 14 anos a maior parte das crianças em idade escolar, que haviam recebido alimentação complementar por intermédio de um projeto de estudo, achando que, apesar de não ter havido intervenções posteriores em sua alimentação, as crianças que receberam a alimentação complementar mantinham sua diferença de estatura e conseguiam melhores resultados nos testes de rendimento".

Outro aspecto significativo são as alterações 
do sistema imunitário nos desnutridos, constituindo a imunidade medida pelos linfócitos $\mathrm{T}$ o setor de resposta imune mais afetado, bem como o prejuízo na síntese ativa de anticorpos (Sampaio, 1987).

Acreditamos que se torna desnecessário ampliar as citações a respeito desses agravos, porque já suficientemente elucidativas dos desdobramentos negativos que podem acarretar para o futuro dessas crianças carentes, influenciando:

- na gravidade e elevada mortalidade por doenças infecciosas;

- na capacidade para concentrar-se e aprender;

- no desenvolvimento do que os psicólogos e pedagogos denominam "características de prontidão", entre as quais a coordenação viso-manual, a discriminação visual e auditiva, a orientação espacial, a ordenação temporal, a memorização e a concentração;

- na repetência e evasão escolar;

- na interação satisfatória com o meio onde vivem;

- na mobilidade ascendente na sociedade.

Enfim, se os especialistas evidenciam que as crianças desnutridas não são bons estudantes, perdem boa parcela dos conhecimentos oferecidos pela escola, têm a atividade física reduzida e inibida a capacidade de enfrentar as demandas da existência no dia-a-dia, cabe indagar:

- não seriam restritas as possibilidades de progresso dessas crianças, levando-as a resultados deficientes na escola, à privação de experiências estimulantes e à perda de oportunidades de aprendizagem?

- quando adultos, não teriam limitadas as condições de acesso ao mercado de trabalho, sujeitando-se a ocupações inferiores no setor produtivo?

- no trabalho, o seu rendimento não seria inferior ao normal, limitando, portanto, a sua expectativa de renda?

- as altas taxas de morbidade e de mortalidade, tendo a desnutrição como causa básica ou associada, não implica aumento dos custos dos compromissos que a população assume para proteger-se?
No tocante à melhoria da capacidade laboral, é bastante esclarecedor o estudo de Serra Leoa, referido em documento da FAO/OMS (1992b), demonstrando que um aumento de $10 \%$ no aporte calórico dos trabalhadores agrícolas aumentou sua produção em $5 \%$.

Não hesitamos em deduzir que esses fatos repercutem na economia. Daí a afirmação de Reutlinger \& Selowsky (1977), de que o estado de nutrição, principalmente na infância, constitui um importante instrumento de política na formação do capital humano.

Vale salientar, em que pese o declínio nos últimos anos, que a desnutrição energético-protéica ainda constitui o mais grave e complexo problema nutricional no país. Porém, outros problemas nutricionais igualmente relevantes trazem repercussões econômicas, que adiante sumariamos em seus delineamentos marcantes (Chahad \& Cervine, 1988; Silva, 1986; Singer, 1988).

De acordo com os dados disponíveis, o Brasil e a Bolívia constituem os dois países sulamericanos em que a hipovitaminose $\mathrm{A}$ ostenta proporções endêmicas, manifestando tendência epidêmica durante as grandes estiagens. Além de estar associada aos elevados índices de mortalidade, os estudos indicam (Unicef, 1980) que cerca de 25\% dos sobreviventes à xeroftalmia grave perdem por completo a visão; cerca de 50 a $60 \%$ ficam parcialmente cegos e somente 15 a $20 \%$ escapam com a visão inalterada. A nosso ver, as conseqüências sociais e econômicas são severas, cabendo apenas ressaltar o pesado fardo que representa para a família e a sociedade a manutenção de um cego.

Surpreendentemente, a prevalência das anemias nutricionais vem aumentando de forma expressiva no país. A anemia reduz a capacidade para as atividades que exigem energia, provocando, por exemplo, a apatia nas crianças e concorrendo, assim, para o fracasso escolar, e quanto mais intensa a anemia maior será a redução do rendimento laboral máximo. A carência de ferro também entorpece a resposta imunitária, reduzindo a capacidade bactericida dos fagócitos e há indícios de alterações da imunidade celular e humoral.

O bócio é um problema nutricional que está praticamente controlado, convindo somente 
registrar a associação com o cretinismo e a surdo-mudez irreversíveis e com a deficiência mental, constituindo, então, um oneroso encargo para a família e a comunidade. Ressalte-se que o bócio representa, ainda, a principal causa de idiotia evitável no mundo.

Finalmente, reforçam estes comentários acerca dos desperdícios humanos e econômicos ocasionados pela desnutrição, os resultados de estudos da FAO/OMS (Berg, 1985) com variáveis múltiplas de dados provenientes de 39 países, chegando a conclusões surpreendentes sobre a deficiência de energia como fator determinante da esperança de vida, do crescimento, da mortalidade infantil e da mortalidade de um a quatro anos.

A temática em foco foi objeto de discussão na Conferência Internacional sobre Nutrição (CIN), realizada em dezembro de 1992, em Roma, sob o patrocínio da FAO e da OMS, onde especialistas de 159 países revisaram e salientaram a grande importância das conseqüências da má nutrição, em suas diversas formas, para o bem-estar humano e o desenvolvimento sócio-econômico.

\section{CONSIDERAÇÕES FINAIS}

Reafirmamos o intuito de não esgotar o assunto, simplesmente oferecer uma base para o exercício da reflexão construtiva.

Em virtude do exposto, é inconteste que os investimentos em nutrição resultam em benefícios econômicos, porque:

- contribuem para um aumento potencial ou efetivo na capacidade produtiva das pessoas;

- liberam o setor saúde de recursos empregados no tratamento de determinadas doenças para aplicação em outro uso alternativo;

- propiciam aumento da freqüência à escola e melhoria dos resultados das inversões em educação;

- concorrem para diminuir a incidência de doenças transmissíveis e redução do número de dias de trabalho perdidos devido a enfermidades;

- em sendo fundamentais para a saúde, o aprendizado, o trabalho e o bem-estar, influenciam fortemente na conduta social da população.
Por conseguinte, procede a assertiva de Musgrove (1993: 124), ao concluir que "os gastos públicos em saúde parecem ser os mais distributivos que qualquer outro gasto público de ordem social".

$\mathrm{Na}$ realidade, a obtenção de elevadas taxas de retorno desses investimentos sugere que quantidades adicionais de recursos devem ser direcionadas para nutrição e saúde.

Todavia, em tempos de crise, sentenciam alguns especialistas (Opas, 1990: 05), “a relação entre saúde e desenvolvimento tem uma face amarga, pois à medida que mais se necessita dar atenção aos problemas sociais mais drásticos são os cortes nos recursos públicos”.

Isto está ocorrendo quando as maiores preocupações convergem para a eficiência e a produtividade, na alavancagem com vistas a desenvolver e modernizar o Brasil.

No quadro de desafios para atingir esses marcos referenciais, desponta o desafio da qualidade que, esclarece Falcão (1993), é também um desafio de desenvolvimento humano e este depende, basicamente, do desenvolvimento da educação.

Para aquilatar a gravidade da situação, diz esse autor que, segundo dados da ONU, apenas $12 \%$ dos trabalhadores brasileiros estariam habilitados para trabalhar numa economia tecnologicamente moderna. Por sua vez, pesquisas de Lima (1993) têm registrado em empresas e organizações, a existência de disfunções que se traduzem financeiramente em custos ocultos de 10 mil a 20 mil dólares americanos por trabalhador e por ano, que poderiam ser transformados em lucro para a empresa e os trabalhadores. E são alarmantes os indicadores de custos ocultos de origem social - absenteísmo, acidentes do trabalho (o Brasil é campeão mundial) e rotatividade de pessoal.

Daí a conclusão de Bezerra (1993), de que não adianta somente investir em alta tecnologia, temos que investir também nas pessoas, pois são os elementos que vão impor o ritmo ao desenvolvimento da qualidade, concorrendo para perpetuá-la.

Numa economia socialmente responsável seria fácil identificar e combater os fatores contributórios para situações tão desastrosas. Então, é preciso insistir no relevante papel da Nutrição no desenvolvimento dos recursos 
humanos e, conseqüentemente, na preservação desse capital, considerado uma variável-chave da modernização e da competitividade.

Será este o cenário que estamos descortinando no país?

Os objetivos do Plano de Combate à Fome e à Miséria conduzem à estimulação do crescimento econômico e do progresso social, promovendo um esforço de organização da sociedade sem precedentes na nossa história.

Desta maneira, vislumbramos um grande potencial de mudanças nos anos finais desta década, com a perspectiva da nutrição figurar bem alto na lista de prioridades nacionais. Sem dúvidas, seria difícil encontrar uma alternativa de investimento mais louvável e compensadora.

Para isso, precisamos ficar atentos aos compromissos assumidos pelos governos dos 159 países participantes da CIN, inclusive o Brasil, que unanimemente aprovaram uma Declaração em que prometeram "revisar ou preparar, antes do final de 1994, Planos de Ação para a Nutrição" (FAO, 1993: 01), acentuando que a melhoria da nutrição deve ser vista como "um objetivo de desenvolvimento por direito próprio e como um meio para consegui-lo" (FAO, 1993: 12), e realçando a necessidade de serem "claros os objetivos nutricionais que devem incorporar-se às políticas e programas de desenvolvimento" (FAO, 1993: 13).

Conclusivamente, os signatários dessa Declaração Mundial enfatizaram que "se reconhece que a pobreza, a desigualdade social e a falta de educação são as causas radicais da má nutrição e se insiste que o melhoramento do bem-estar humano, incluído o nutricional, hão de ser o eixo dos esforços do desenvolvimento social e econômico" (FAO, 1993: 01).

Para finalizar, cabe repetir as judiciosas palavras de Josué de Castro (Castro, 1984: 91), o qual alertava para que os planos "não sejam uma espécie de cartão de visita do governo", "como um jogo de palavras que poderia cobrir a ineficácia de uma ação até hoje mal conduzida" (Castro, 1984: 100).

\section{RESUMO}

ARRUDA, I. K. G. \& ARRUDA, B. K. G. Nutrição e Desenvolvimento. Cad. Saúde Públ., Rio de Janeiro, 10 (3): 392-397, jul/set, 1994.

As discussões sobre desenvolvimento e nutrição freqüentemente se realizam sob um duplo enfoque: aqueles que consideram o estado nutricional como reflexo do desenvolvimento, e os que admitem que a nutrição influencia fortemente no nível e ritmo desse desenvolvimento. Os autores focalizam o tema visualizando a nutrição como um fator decisivo para um bom desenvolvimento social e econômico, particularizando o fato de que as intervenções nutricionais podem contribuir para melhorias significativas nos resultados escolares, na produtividade do trabalho e na resistência às infecções. Assim, os reflexos da desnutrição na economia seriam evidentes: quer pelas limitações na expectativa de renda, quer pelo aumento dos custos dos compromissos que a população assume para proteger-se, quer pelos avultados custos ocultos de origem social absenteísmo, acidentes do trabalho e rotatividade de pessoal. Em face dos propósitos de modernização e competitividade da economia, é inquestionável a necessidade da nutrição figurar bem alto na lista de prioridades nacionais. Com isso, promover-se-ia o desenvolvimento dos recursos humanos e a preservação desse capital, que é o ideário de uma economia socialmente responsável.

Palavras-Chave: Nutrição; Desenvolvimento; Políticas Públicas; Recursos Humanos

\section{REFERÊNCIAS BIBLIOGRÁFICAS}

BERG, A., 1974. Nutrição e desenvolvimento econômico. Diálogo, Rio de Janeiro, 3: 55-62.

BERG, A., 1975. Estudios sobre Nutricion: su importancia en el desarrollo económico. México, DF: Editorial Limusa.

BERG, A., 1981. Los Malnutridos. Washington, DC: The World Bank. 
BEZERRA, J. C., 1993. O desenvolvimento dos recursos humanos na busca da perpetuação da qualidade. In: Gerenciamento da Qualidade - O Caminho para a Modernização, pp. 10-21, Rio de Janeiro: CNPq/Fundação Roberto Marinho/Grupo Gerdau.

CASTRO, A. M. (Org.), 1984. Fome, um Tema Proibido. Últimos Escritos de fosué de Castro. Petrópolis: Vozes.

CHADAD, J. P. Z. \& CERVINE, R.(Orgs.), 1988. Crise e Infância no Brasil. São Paulo: Unicef IPE/USP.

FAO (Organização das Nações Unidas para a Agricultura e a Alimentação), 1993. Directrices para la Formulación de Planes Nacionales de Acción para la Nutrición. Conferência Internacional sobre Nutrição. Roma: FAO.

FAO (Organização das Nações Unidas para a Agricultura e a Alimentação)/OMS (Organização Mundial de Saúde), 1992a. Elementos Principales de Estrategias Nutricionales. Documento Temático, $\mathrm{n}^{\mathrm{o}} 1$ - mejora de la seguridad alimentaria en los hogares. Roma: FAO. (Mimeo.) 1992b. Elementos Principales de Estrategias Nutricionales. Documento Temático, $\mathrm{n}^{\circ} 8$ - Incorporación de los objetivos de nutrición en las politicas de desarrollo. Roma: FAO. (Mimeo.) 1992c. Nutrición y Desarrollo Una Evaluación Mundial. Roma: FAO. (Mimeo.)

FALCÃO, J., 1993. Prefácio. In: Gerenciamento da Qualidade - O Caminho para a Modernização, pp. 06, Rio de Janeiro: CNPq/ Fundação Roberto Marinho/Grupo Gerdau.
HAKIM, P. \& SOLIMANO, G., 1976. Nutrição e desenvolvimento nacional: estabelecendo a conexão, In: Fome e Desnutrição: Determinantes Sociais (F. L. S. Valente, org.), pp. 29-47, São Paulo: Cortez.

LIMA, M. A. A., 1993. Qualidade e tecnologia: binômio estratégico para a modernização do Brasil. In: Gerenciamento da Qualidade O Caminho para a Modernização, 22-49, Rio de Janeiro: CNPq/Fundação Roberto Marinho/Grupo Gerdau.

MUSGROVE, P., 1993. Relaciones entre la salud y el desarrollo. Boletin de la Oficina Sanitaria Panamericana, 114: 115-129.

OPAS (Organização Panamericana de Saúde), 1990. Orientaciones Estrategicas y Prioridades Programaticas en el Cuadrienio 1991-1994. Washington, D.C.: OPAS. (Mimeo.)

REUTLINGER, S. \& SELOWSKY, M., 1977. Desnutrición y Pobreza: Magnitudes y Opciones de Politica. Madrid: Editorial Technos.

SILVA, P. R., 1986. Nutrição e Desenvolvimento Econômico do Nordeste Brasileiro. $2^{\circ}$ ed., Fortaleza: ETENE. (Série Estudos Econômicos e Sociais, 25)

SAMPAIO, M. M. S. C., 1987. As imunodeficiências do dia-a-dia. Fornal de Pediatria, 62 (1/2): 04.

SINGER, P., 1988. Implicações da desnutrição no desenvolvimento econômico. Caderno Nesp, Brasília, 1: 11-19.

UNICEF (Fundo das Nações Unidas para a Infância), 1980. Carência de Vitamina $A e$ Xeroftalmia.

Brasília, DF: Unicef. (Technical Report Series, 590) 